\section{Chaos theory and a career in medicine}

\author{
Marc Lippman
}

(Correspondence should be addressed to M Lippman MD MACP; Email: mlippman@med.miami.edu)

\section{Endocrine-Related Cancer (2012) 19 P1-P3}

'In chaos theory, the butterfly effect is the sensitive dependence on initial conditions; where a small change at one place in a nonlinear system can result in large differences to a later state. The effect derives its name from the theoretical example of a hurricane's formation being contingent on whether or not a distant butterfly had flapped its wings several weeks before.

Although the butterfly effect may appear to be an esoteric and unusual behavior, it is exhibited by very simple systems: for example, a ball placed at the crest of a hill might roll into any of several valleys depending on slight differences in initial position'.

I have to think that my own career is a validation of the Butterfly Effect. Obviously, there are so many crossroads, so many possibly turnings, so many pins in the Pachinko game board where one might have taken a different course. On the other hand, as I hope to make clear, a series of personal circumstances and the state of science when I entered the field made so much of my career path almost obvious and unavoidable in retrospect.

I owe a great deal to my father. He was a remarkably gifted man. Some might say a polymath. He was a fine physician, a scholar, a renowned collector of African tribal art, a cultivator of orchids, and a wonderful photographer. He had multiple virtues that he modeled for me over and over again. He gave a day a week gratis from his private practice to train residents at SUNY Downstate. He worked amazingly long hours in his office, which was part of our house, from 8 in the morning till 9 at night with an hour off for dinner, and a half day every Saturday. He deeply believed in 'professional courtesy' and felt physicians were obligated to take care of each other for free along with their families - a huge commitment for a

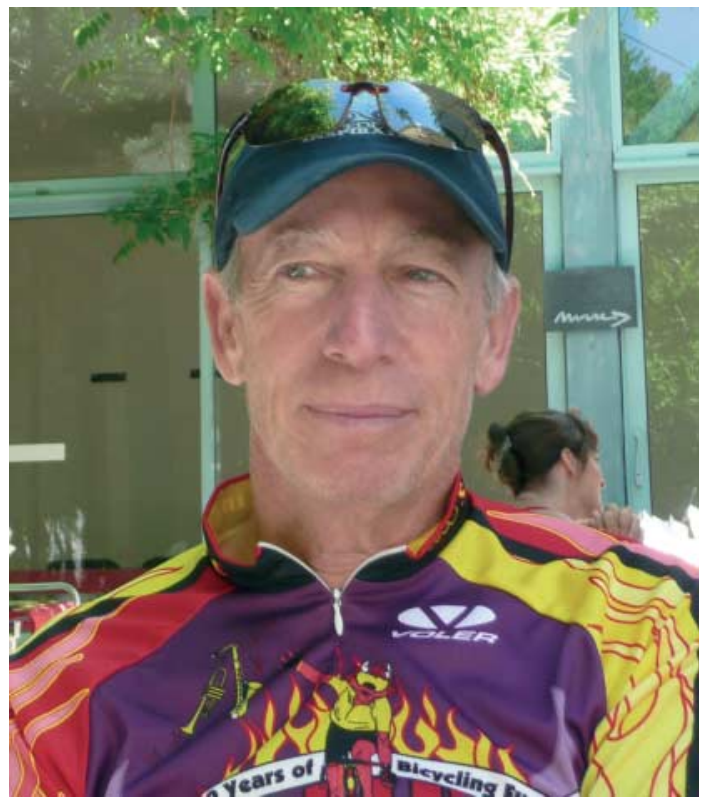

psychiatrist. He took me on consulting rounds in neurology, which he also practiced, and to New York state psychiatric hospitals in the era before neuroleptics, which made an indelible impression of human suffering on me as a 7-year-old child.

There was no question one could ask about anything, which, if asked in a serious way, would not result in the most careful consideration and response. Our dinner table was always a place for discussion and no matter how feebly put, any question about anything that was seriously asked was seriously answered, often with follow-up after suitable attention had been devoted to it.

I remember when I was no more than about 7 going to a car wash with him. We walked outside along the path the car was towed peering in and watching the various soapings and rinsings. Suddenly my father stopped and unabashedly stood still watching a man a few yards off changing the tire of a car on a jack. He said to me 'watch that man'. I stood there and watched the near ballet-like perfection with which the man twirled the x-shaped tire iron, the lug nuts literally dancing off the tire into the waiting hubcap. Not a wasted motion. When we had walked on my father said: 'you will never see a tire changed like that. That is the best that task can be done. It's something to admire. That man had style'. I love that about my father. His tireless ability to see the grace and beauty in almost anything around him when it was done well.

So it is hardly a surprise that I 'always' knew I would be a physician and that I would be a scientist. I always wanted to be both. The only question really was what 
path that might take. If you can place yourself in the era when I went to medical school (1964-1968), it is a little easier to understand why perhaps the choices I made were perhaps less chancy than might appear at first glance. In those days, we knew so very little about what caused almost any disease with the major exception of infectious diseases. There we had Koch and he had served us well. But for most other diseases, things were still pretty vague. I well recall being 'taught' that ulcers were caused by stress, heart disease by stress, inflammatory bowel disease by stress, certainly asthma was caused by stress, etc. What really changed things at the time for me was the development of RIA and radioreceptor assays. Suddenly we had the means to measure molecules at what seemed like unimaginably low concentrations. In an amazingly exciting brief period, a whole raft of endocrine illnesses ranging from acromegaly to Addison's disease were all worked out in terms of their pathophysiology. There was almost no doubt in my mind as I went through medical school that endocrinology would lead the way in terms of scientific understanding of disease pathophysiology and I was almost sure that I wanted to be an endocrinologist. Except for one thing.

At Yale, it was a requirement that one did a thesis to graduate and I became strongly interested in the work of one of my professors, Stuart Finch, who was working on leukocyte kinetics. The attraction for me was not so much the biochemistry he was exploring as the mortal illnesses he treated. At this time, systemic management of cancer was virtually nonexistent. A few single agents like 5FU, 6MP, methotrexate, nitrogen mustard and glucocorticoids existed and that was essentially it. The very first combination studies that would for the very first time suggest we could cure a few people were underway in the leukemias and lymphomas. I was fascinated by the challenges - both medical and emotional - of managing these very difficult patients and from then on felt that I would try to figure out a path to combining my love of the rational science I felt existed in endocrinology with the huge challenges of malignancy.

This was the Viet Nam era and I was lucky enough to get into the PHS so I could work at the NCI. Because of my thesis I was recruited by the leukemia service of the $\mathrm{NCI}$ and spent one of the most arduous years of my life on a leukemia ward. I didn't have a single remission that year. There were nights where every single patient on my service was on triple antibiotics for febrile neutropenia or worse. We didn't have ICU's. Our single agent trials were well intended and invariably unsuccessful.
At the same time I was taking the molecular endocrinology courses offered. This was the golden age of endocrinology and giants like Jesse Roth and Mort Lipsett were all there. I was amazingly fortunate to strike up a friendship with Brad Thompson in the Laboratory of Biochemistry who was one of the teachers of the molecular endocrinology course (which I would ultimately inherit with Ron Kahn!) and decided I would work with him. Brad was fantastic and he allowed me to develop a completely independent area of exploration. I measured glucocorticoid receptors in leukemia and we showed their existence and their correlation with disease progression. Obviously this was a fusion of my interest in oncology and endocrinology and I still believe amongst some of the best work I have ever done. I owe a great deal to Brad who to this day represents what I think is the very best in scientific curiosity and integrity.

When my NIH time was done, I was board-eligible in oncology but still needed endocrine training. I loved Yale and thought I would go back there and finish my training and try for a faculty position. Yale was small then, and true giants like Pat Mulrow, Phil Bondy, Gerry Burrow, and most of all Phil Felig were amazingly generous with their time and inspirational knowledge. But I remained torn between endocrinology and oncology, liking the former for the science and the latter for the sheer existential magnitude of the illness. One has to recall at this time there was little if any relationship between the two fields. The last session at the Endocrine Society was hormones and cancer (usually when everyone had gone home it seemed) and at AACR the session was cancer and hormones, also poorly attended. ASCO had barely begun.

I was casting about for where to start my academic career. I looked at multiple assistant professorships in endocrinology but then I was called by the NCI and asked would I join the newly formed Breast Cancer Section of the medicine branch. I leapt at it. Here was the chance I sought. A disease in which endocrinology was obviously critical with all of the challenges that breast cancer provided at a time when over half of all women diagnosed with the disease would succumb to it eventually.

And frankly I got lucky. Very lucky. I tried to do something that no one in their right mind in the modern era of grant funding would try. I didn't build on any particular work I had done at the NCI or Yale. Instead I felt that if I could develop a model of human breast cancer that was hormone dependent I would have something really worthwhile. So I set about establishing one and after a year of work I knew we had it. I can 
still recall as though it were yesterday popping the vials into the liquid scintillation counter and literally sitting atop the adjacent ultracentrifuge watching the counts come up one by one. So impatient that I would initially do 15 -second counts just to 'see' if it had worked.

And then something else happened that was truly serendipitous. It turned that almost no one else could reproduce this and what seemed like a gazillion hostile papers and publications rained down challenging the findings. Easy in retrospect to know how hard the experiments were to do because of contaminating estrogens in serum and media effects but when it really did become clear that we had been right all along that surely made much of the rest of my career a lot easier.

In some sense that's the whole story. I have remained in this area in one form or another my entire career. I don't regret any of it. I have lived in an era in which the management of a disease has utterly changed and come to a place in which the majority of women diagnosed with breast cancer are cured. I am ever so deeply proud and satisfied that some of the best young people imaginable choose to work with me in those heady days at the NCI and afterwards. These are colleagues who are now amongst the most renowned in their own right in the world. In the lovely musical The King and I, the wonderful lyric: 'if you become a teacher by your students you'll be taught...' occurs. Truer words were never spoken. I consider myself incredibly lucky and helped by these deeply felt relationships that have gone from trainees and students to their current status in which I can now bask in their reflected glory. I number some very talented people among many others: Larry Norton, Nancy Davidson, Marie Monaco, Kent Osborne, Kevin Cullen, Ed Gelmann, George Wilding, Doug Yee, Neal Rosen, Sandy Swain, Raimund Jakesz, Cornelius Knabbe, Andre Lacroix, Susan Bates, Soon Paik, Ruth Lupu, Marco Gottardis, Nils Brunner, Matt Ellis, Rob Clarke, Leena Clarke, Erik Tompson, Mike Johnson, James Rae, Anton Wellstein, Mary Beth Martin, and Claudine Isaacs.

I must very specifically mention Bob Dickson who joined my lab after finishing a post doc with Ira Pastan and over the ensuing twenty years was my close friend and colleague with whom I published over 100 papers. His tragic death cut short the life of one of the most decent and dedicated people I have ever known. He is sorely missed.

I don't know if this collection of recollections on a career has any particular value to others but I am grateful for the opportunity it has given me to try to better understand my own professional path.

\section{Declaration of interest}

The author declares that there is no conflict of interest that could be perceived as prejudicing the impartiality of this profile.

\section{Funding}

This profile did not receive any specific grant from any funding agency in the public, commercial or not-for-profit sector. 